\title{
Direitos das mulheres e a encontrabilidade da informação no portal da câmara dos deputados: perspectivas brasileiras rumo à Agenda 2030 das Nações Unidas
}

\author{
Carla Maria Martellote Viola \\ Universidade Federal do Rio de Janeiro (UFRJ), Brasil \\ Marco André Feldman Schneider \\ Universidade Federal do Rio de Janeiro (UFRJ), Brasil
}

COMMUNICATIONS

\begin{abstract}
Resumo
Objetivo. O objetivo do artigo é averiguar se o trabalho desenvolvido pelas/os profissionais da informação e documentação, na Arquitetura da Informação do portal da Câmara dos Deputados, está permitindo a Encontrabilidade da Informação que auxilie o alcance dos objetivos apregoados na Agenda 2030, no que tange aos Direitos das Mulheres.

Método. A pesquisa é exploratório-avaliativa com delineamento bibliográfico e abordagem qualitativa.

Resultados. Foram identificadas quatro interfaces/fontes de pesquisa na Arquitetura da Informação do portal da Câmara dos Deputados com possibilidades de encontrabilidade de informações semelhantes sobre os Direitos das Mulheres, que ora se completam, ora se apresentam conflituosas, exigindo que os dados legislativos disponibilizados sejam confirmados, a partir da verificação de autoria das proposições, datas de propositura, tramitação e arquivamento ou conversão em lei. Conclusões. Conclui-se que o portal analisado não possui uma Arquitetura da Informação plenamente eficaz, por conter informações pervasivas, repetidas e equivocadas em quatro ambientes diferentes, não possuindo classificação eficiente, que se perfaça na Encontrabilidade da Informação precisa e efetiva. As/os profissionais da informação e documentação do portal devem reavaliar a taxonomia, enquanto estrutura classificatória para organização do conhecimento, no que tange aos interesses e Direitos das Mulheres e em atenção aos objetivos descritos na Agenda 2030, considerando, ainda, os atributos da Competência em Informação e da Ética em Informação.
\end{abstract}

Palavras-chave:

Agenda 2030; Arquitetura da informação; Direitos das mulheres; Encontrabilidade da informação; Portal da câmara dos deputados; Profissionais da informação e documentação.

Women's rights and the findability of information on the portal of the chamber of deputies: Brazilian perspectives towards the United Nations 2030 Agenda

\begin{abstract}
Objective. The article objective is to find out if the work developed by the information and documentation professionals, in the Information Architecture from the Chamber of Deputies' portal, is allowing the Information Findability that helps to reach the objectives proclaimed in the Agenda 2030, regarding Women's Rights.

Method. The research is exploratory-evaluative with a bibliographic design and a qualitative approach.

Results. Four research interfaces/sources were identified in the Information Architecture, from the Chamber of Deputies' portal, with possibilities of finding similar information on the women's rights, which are now complete, sometimes conflicting, requiring that the legislative data made available be confirmed, from the verification of proposals authorship, dates of filing, processing and filing or conversion into law.

Conclusions. It is concluded that the analyzed portal does not have a fully effective Information Architecture, because it contains pervasive, repeated and misleading information in four different environments, and does not have an efficient classification, which is perfected in the finding of accurate and effective information. The information and documentation professionals of the portal should reevaluate taxonomy, as a classificatory structure for the organization of knowledge, regarding women's interests and rights, taking into account the objectives described in the Agenda 2030, also considering the attributes of Information Competence and Information Ethics.
\end{abstract}

Keywords:

Agenda 2030; Chamber of deputies' portal; Information architecture; Information and documentation professionals; Information findability; Women's rights. 
Women's rights and the findability of information on the portal of the chamber of deputies: Brazilian perspectives towards the United Nations 2030 Agenda

\title{
1 Introdução
}

A Agenda 2030 das Nações Unidas reúne 17 objetivos para se alcançar o desenvolvimento sustentável e 169 metas que demonstram a escala e a ambição de uma agenda universal. Os objetivos e metas são integrados, indivisíveis e equilibram as três dimensões do desenvolvimento sustentável: a econômica, a social e a ambiental (ONUBR, 2015).

O processo rumo à agenda de desenvolvimento 2030, cuja implementação teve início a partir de 2015, foi liderado pelos Estados-membros, com a participação dos principais grupos e partes interessadas da sociedade civil. A agenda reflete os novos desafios de desenvolvimento e está ligada ao resultado da Rio+20 - a Conferência da ONU sobre Desenvolvimento Sustentável - que foi realizada em junho de 2012, no Rio de Janeiro, Brasil.

AAgenda 2030, que descreve os Objetivos do Desenvolvimento Sustentável (ODSs) e suas metas, evidencia, no objetivo 5, a preocupação mundial com as discrepâncias entre homens e mulheres, descrevendo como finalidade "alcançar a igualdade de gênero e empoderar todas as mulheres e meninas" (ONUBR, 2015).

De acordo com a Organização das Nações Unidas (2015), em seu portal Brasil, com as perspectivas do objetivo 5, espera-se:

\begin{abstract}
acabar com todas as formas de discriminação contra todas as mulheres e meninas em toda parte; eliminar todas as formas de violência contra todas as mulheres e meninas nas esferas públicas e privadas, incluindo o tráfico e exploração sexual e de outros tipos; eliminar todas as práticas nocivas, como os casamentos prematuros, forçados e de crianças e mutilações genitais femininas; reconhecer e valorizar o trabalho de assistência e doméstico não remunerado, por meio da disponibilização de serviços públicos, infraestruturas políticas de proteção social, bem como a promoção da responsabilidade compartilhada dentro do lar e da família, conforme os contextos nacionais; garantir a participação plena e efetiva das mulheres e a igualdade de oportunidades para a liderança em todos os níveis de tomada de decisão na vida política, econômica e pública; assegurar o acesso universal à saúde sexual e reprodutiva e os direitos reprodutivos, como acordado em conformidade com o Programa de Ação da Conferência Internacional sobre População e Desenvolvimento, e com a Plataforma de Ação de Pequim e os documentos resultantes de suas conferências de revisão; realizar reformas para dar às mulheres direitos iguais aos recursos econômicos, bem como o acesso à propriedade e controle sobre a terra e outras formas de propriedade, serviços financeiros, herança e os recursos naturais, de acordo com as leis nacionais; aumentar o uso de tecnologias de base, em particular as tecnologias de informação e comunicação, para promover o empoderamento das mulheres; adotar e fortalecer políticas sólidas e legislação aplicável para a promoção da igualdade de gênero e o empoderamento de todas as mulheres e meninas em todos os níveis (ONUBR, 2015).
\end{abstract}

Em conformidade com tal objetivo, está a atenção com a qualidade da informação. A declaração, no item 15, alerta que:
a disseminação da informação e das tecnologias da comunicação, bem como da interconectividade global, têm um grande potencial para acelerar o progresso humano, para eliminar o fosso digital e para o desen- volvimento de sociedades do conhecimento, assim como a inovação científica e tecnológica em áreas tão diversas como medicina e energia (ONUBR, 2015).

Nessa perspectiva, a estrutura e a dinâmica das práticas em ambientes digitais que envolvem a Encontrabilidade da Informação (EI) e Arquitetura da Informação (AI) estão permeadas por artefatos e plataformas, que possibilitam aos cidadãos pesquisas nas instâncias pública e privada. Esse novo paradigma é um fenômeno global que afetou diretamente a recuperação, comunicação e o fluxo das informações, fato que impulsionou estudos em várias áreas científicas a fim de investigar a interdisciplinaridade da informação.

Saracevic alerta que, em razão da "explosão informacional, a recuperação da informação tornou-se uma solução bem-sucedida encontrada pela Cl [Ciência da Informação] e em processo de desenvolvimento até hoje" (SARACEVIC, 1996, p. 44). De pronto, a informação precisa ser encontrada e recuperada, esclarecendo que neste momento, os sistemas de recuperação utilizados não mudam o conhecimento, a princípio, sobre esta informação. As/os profissionais da informação e documentação ou mesmo integrantes da sociedade civil estão diante da existência ou não da informação, da localização e do acesso ou não do documento pesquisado.

Para tanto, a gestão da informação, na era contemporânea, evidencia profundas mudanças no comportamento da sociedade e dos gestores governamentais, influindo diretamente nas atividades sociais, culturais, econômicas e políticas da atualidade. As/os profissionais da informação e documentação têm relevante importância, tanto na Al 
quanto na organização da informação, devendo disponibilizar as informações em interfaces amigáveis e interativas para a adequada Encontrabilidade da Informação, seja para uso social, profissional ou acadêmico.

No que tange à igualdade de gênero e à informação para atender a Agenda 2030, entre outras ações que abrangem a economia, o social e a cultura, está a disseminação de informações que atendam as mulheres quanto aos seus direitos. A legislação brasileira está em constante modificação no âmbito legislativo e os trâmites informacionais que envolvem proposições, debates e atualizações são dispostos no portal da Câmara dos Deputados. Esse compêndio de informações precisa ser encontrado.

Além disso, acredita-se que a análise de atributos e referências sobre informações torna-se mais profícua quando tratada por profissionais da informação e documentação que possuem competências específicas para o tratamento de questões relacionadas à $\mathrm{Al}$ e à El. Essas/es profissionais reúnem tanto a competência teórica da ciência pura, uma vez que problematizam um assunto sem considerar a imediata aplicabilidade, como também a competência prática da ciência aplicada, para gerir, organizar e acessar documentos visando a conformação das informações para atender a sociedade.

Visando esclarecimentos dos meandros das questões descritas, o objetivo geral deste artigo é averiguar se o trabalho desenvolvido pelas/os profissionais da informação e documentação, na Al do portal da Câmara dos Deputados, está permitindo uma Encontrabilidade da Informação que englobe as proposições que, acessadas, mapeadas e classificadas por cidadãs/ãos, profissionais e estudantes, evidencie um panorama transparente e que tenha a predisposição de atender aos ODSs, da Agenda 2030 das Nações Unidas, no que tange à igualdade de gênero e empoderamento de todas as mulheres e meninas e à disseminação da informação.

Como objetivos específicos, pretende-se identificar e descrever as interfaces/fontes disponibilizadas para acesso a dados/informações digitais pelo portal da Câmara dos Deputados; evidenciar aspectos sobre a Al que permitam ou não o acesso inclusivo, empoderado, plural e equitativo à informação; e verificar interfaces que possibilitem a pesquisa pela sociedade.

\section{Revisão de literatura}

Os ODSs representam um grande desafio para as/os profissionais da informação e documentação, pois a sociedade tem a necessidade cada vez maior de ser informada sobre ações que estão sendo propostas e efetivadas para que o Brasil os atinja, assim como as metas propostas pela Agenda 2030. Os ODSs entraram em vigor em $1^{\circ}$ de janeiro de 2016 e espera-se que sejam cumpridos até 31 de dezembro de 2030. Entretanto, há a expectativa de que algumas metas, baseadas em acordos internacionais, sejam cumpridas antes do prazo estabelecido.

A Lei de Acesso à Informação (LAI) trouxe um grande avanço na disseminação de informação pública no Brasil, permitindo novos estudos da El. O termo "encontrabilidade" foi cunhado a partir do termo em inglês "findability", proposto pelo arquiteto da informação Peter Morville, em 2005, em seu livro Ambient findability: what we find changes who we become.

Segundo Morville (2005), "findability" se refere à capacidade de uma informação ser encontrada em um ambiente informacional a partir da qualidade (ser localizável ou navegável); do grau com o qual um determinado dado é descoberto ou localizado nesse ambiente; e, também, do grau no qual esses sistemas suportam a navegação e a recuperação.

Morville (2005) aduz que um dos grandes problemas da web é a "findability" e que a Al é parte importante da solução. Também assevera que as tecnologias atuais possibilitam que qualquer coisa seja encontrada, em qualquer lugar, por qualquer um e a qualquer momento.

O tema El também foi desenvolvido por Vechiato em sua tese no campo da Ciência da Informação (Cl). O autor defende que a encontrabilidade é "um importante elemento que se situa entre os ambientes e sistemas de informação e os sujeitos informacionais, a qual pode ser investigada no âmbito da Cl na perspectiva da mediação, visto que esta perpassa os processos que compõem o fluxo infocomunicacional" (VECHIATO, 2013, p. 9). 


\begin{abstract}
Epistemologicamente, a encontrabilidade da informação se insere na Ciência da Informação no paradigma pós-custodial, que privilegia o acesso à informação e é significativamente influenciado pelas Tecnologias da Informação e Comunicação. Teoricamente, o conceito 'encontrabilidade da informação' deriva da evolução da Web na perspectiva das dimensões da linguagem e do conceito de mediação infocomunicacional (VECHIATO; VIDOTTI, 2014b, p. 55).
\end{abstract}

Com efeito, é importante considerar a "dimensão interdisciplinar da área [Cl] sem que se perca de vista o seu próprio foco: propiciar o processo comunicacional entre o produtor do conhecimento e aquele que dele se apropria para a geração de um novo conhecimento" (GUIMARÃES, 2008, p. 92). Nesse sentido, a El está presente nos campos da biblioteconomia e também da comunicação e computação, resultando na produção de conhecimento para cidadãs/ãos, profissionais e estudantes.

O conceito de Encontrabilidade da Informação é fruto do cenário paradigmático que privilegia o acesso à informação com ênfase nas necessidades, competências, comportamentos e características dos usuários para a organização da informação (VECHIATO; VIDOTTI, 2014a, 2014b).

Para tanto, "a encontrabilidade da informação sustenta-se fundamentalmente entre as funcionalidades de um ambiente informacional e as características dos sujeitos informacionais" (VECHIATO; VIDOTTI, 2014b, p. 164), conforme conceito apresentado por Vechiato e Vidotti.

Em vista disso, Viola alega que:

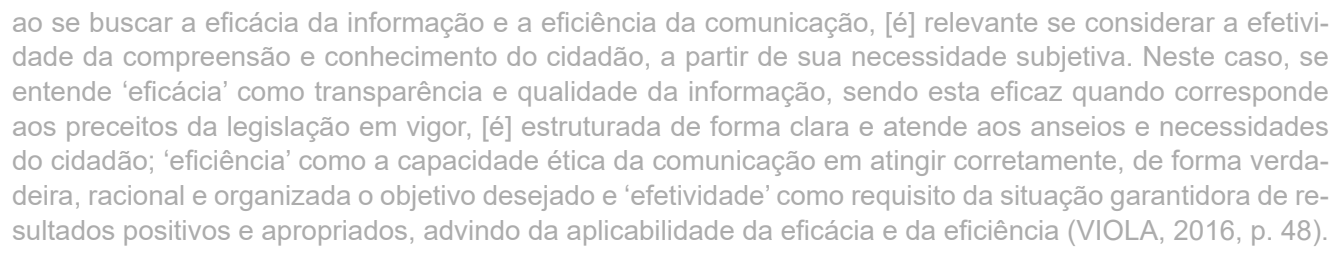

Fundada nesse argumento, a Encontrabilidade da Informação se perfaz nos três "Es" do campo da Administração: eficiência, eficácia e efetividade. E tem, como premissa básica, o objeto e o objetivo em consonância com o subjetivo.

Além do exposto, a produção de conhecimento que é disponibilizada pelo portal da Câmara dos Deputados sobre os Direitos da Mulheres, aqui investigada, também foi analisada em razão da Al, segundo os ensinamentos de Morville e Rosenfeld (2006).

Os autores apresentam, em sua obra Information architecture for the world wide web, a Al nas estruturas informacionais dos espaços digitais. Para Morville e Rosenfeld, Al conforma as informações que serão compartilhadas em websites e pode ser compreendida por três perspectivas: (1) a combinação de cinco sistemas interdependentes sistema de organização (organization system), sistema de rotulação (labeling system), sistema de navegação (navigation system), sistema de busca (search system) e o quinto sistema, denominado de tesauros, vocabulários controlados e metadados (thesauri, controlled vocabularies, and metadata) em websites e intranets; (2) o desenho estrutural de ambientes informacionais compartilhados; e (3) a arte e a ciência de estruturar produtos de informação e experiências que permitam usabilidade e encontrabilidade (MORVILLE; ROSENFELD, 2006).

Destarte, a Al é uma disciplina emergente em uma comunidade profissional focada em trazer princípios de design e arquitetura para a paisagem digital.

O Information Architecture Institute (2020) entende Al pelos seus aspectos funcionais. Para o instituto, Al é a prática de decidir como organizar as partes de algo para ser compreensível; a ajuda às pessoas a entenderem o ambiente e a encontrar o que estão procurando, tanto no mundo real quanto online. Praticar Al envolve facilitar as pessoas e organizações, com as quais se trabalha, a considerar suas estruturas e idioma com atenção. $\mathrm{E}$ a disseminar a missão de divulgar a importante prática da Al, para que mais pessoas tenham as palavras para este trabalho e, portanto, possam educar melhor a si mesmas e a outras pessoas.

Rosenfeld e Morville (2006) apresentam, também, uma lista de disciplinas que fazem fronteiras com a Al, a saber: design gráfico e design de interação, biblioteconomia e ciência da informação, jornalismo, engenharia de usabilidade, marketing, ciência da computação, redação técnica, arquitetura e gerenciamento de produtos. Por causa dessa peculiaridade interdisciplinar, a Al reúne profissionais e titulações acadêmicas variados. 
A partir dos fundamentos e princípios apresentados sobre a El e da Al, é importante citar a explicação de Guimarães, "aspectos contextuais, ligados à formação e à atuação profissional na área [da Cl] passam a ser também objeto de especial reflexão, notadamente no que tange a competências, habilidade e valores éticos envolvidos" (GUIMARÃES, 2008, p. 92).

Desenvolver habilidade e competência no que tange à informação, não é tarefa simples. Exige, além do conhecimento de tecnologias e técnicas para o uso da informação, a capacidade de avaliar, de forma crítica, os campos político-sociais e econômicos. Além disso, a/o profissional que tem acesso e compreende a diversidade de informações no seio de uma sociedade heterônoma qualifica a autonomia de sua profissão, que se perfaz na sua própria cidadania e na daqueles com quem o primeiro compartilha as informações.

Nessa perspectiva, buscando equacionar os Direitos das Mulheres e a necessidade de informação por parte das/ os cidadã/ãos e a obrigatoriedade que o governo tem de divulgá-la, opta-se por, assim como propõe Schneider, "trabalhar a informação enquanto saber, ao mesmo tempo representacional e performático, cujo ciclo de vida sofre as seguintes metamorfoses: percepção, pensamento, registro, circulação, acesso, decodificação, pensamento, uso" (SCHNEIDER, 2013b, p. 62).

A tal reflexão, soma-se o estudo de Capurro sobre a análise genealógica da informação como categoria antropológica inspirada nas pesquisas de Foucault, na qual não se leva em consideração apenas a avaliação histórica, mas também a avaliação crítica da situação na era contemporânea. O autor alega que "nossa estrutura de informações é caracterizada por uma pluralidade de mensagens e mensageiros, onde a questão do poder (manipulação, monopólio, desorientação) dentro de uma nova ordem de informação social ainda está aberta" (CAPURRO, 1996, tradução nossa).

Essa informação que se divide entre individual e coletiva, pública e privada passou a representar, no âmbito público, um desafio para governos, governantes e a governança de qualidade. O acesso à informação pública em nível nacional passou a ser uma realidade para a gestão da informação pública, exigindo adequações jurídicas e administrativas.

A conjuntura de visibilidade e desvelamento de dados públicos possibilitou às mulheres conhecer aspectos de sua condição político-social, favorecendo, assim, a implementação de ações mais eficientes.

De acordo com os preceitos da ONU (2015) sobre igualdade de gênero, e dentro das novas perspectivas globais de transparência das informações públicas, é recomendável que as instituições públicas brasileiras concedam as mesmas oportunidades para capacitação de mulheres e homens, promovendo as mesmas condições de acesso às diversas carreiras e funções oferecidas no mercado de trabalho, incluídas as que envolvem a ciência e tecnologia.

Em atenção à realidade brasileira da educação, do trabalho, dos processos políticos, das circunstâncias sociais e das normativas jurídicas permeadas pelas TICs, faz-se necessário ampliar a capacidade perceptiva e sensitiva das/os profissionais da informação e documentação para análise, com o devido discernimento, das informações oriundas dos ambientes público e privado. Premente é que todas/os as/os profissionais da informação e documentação sejam efetivamente competentes em informação em suas especificidades. Esses/as profissionais devem possuir habilidades para tratar das mínimas nuances da informação que pretende comunicar, conhecer o público para qual a informação se destina e produzi-la de forma adequada.

Cabe destacar que a noção de Competência em Informação ou Competência Informacional, como fazem referência Vitorino e Piantola, "é marcada pela identificação e exploração de uma variedade de paradigmas, os quais a vinculam aos estudos cognitivos, construtivistas e pelo interesse por estudos baseados na esfera do trabalho" (VITORINO; PIANTOLA, 2011, p. 138).

Brisola, Schneider e Silva Junior (2017) assinalam que o entendimento sobre Competência em Informação já é abordado pela $\mathrm{Cl}$ desde 1970, sob a exegese da pedagogia e da biblioteconomia, expandindo-se mais tarde para o uso das redes digitais e das mídias.

Botelho-Francisco acrescenta que, de acordo com trabalho desenvolvido pela UNESCO, a/o profissional competente em informação deve "definir e articular as necessidades de informação, localizar e acessar informações, 
avaliar as informações, organizar a informação; fazer uso ético da informação; comunicar informações; usar habilidades com as TICs para o processamento de informações" (BOTELHO-FRANCISCO, 2017, p. 13).

À vista disso, a aprendizagem de como usar a informação é condição para o desenvolvimento de conhecimentos e habilidades e o estímulo do raciocínio. Além de encorajar o pensar sobre os problemas encontrados por diferentes ângulos, ainda auxilia o crescimento intelectual e gera transformações positivas na sociedade.

De acordo com a Association of College and Research Libraries (ACRL), Competência em Informação é "um conjunto abrangente de habilidades, que englobam a descoberta reflexiva da informação, a compreensão de como a informação é produzida, valorizando o uso da informação na criação de novos conhecimentos e a participação ética nas comunidades de aprendizagem" (ACRL, 2016, p. 3, tradução nossa).

Além disso, analisar a informação recebida ou emanada requer necessariamente adaptação contínua das/dos profissionais da informação e documentação da $\mathrm{Cl}$ às tecnologias emergentes, fato que propicia o engajamento dessas/es profissionais como produtoras/es, colaboradoras/es e distribuidoras/es de ações positivas que possibilitam a compreensão e a reflexão necessárias para atuar em ambiências digitais pública e privada e no mercado de trabalho.

Assim, segundo Elmborg, um indivíduo competente em informação é capaz de:

Determinar a extensão das informações necessárias, acessar a informação necessária de forma eficaz e eficiente, avaliar criticamente as informações e suas fontes, incorporar informações selecionadas em sua base de conhecimento, usar a informação de forma eficaz para realizar um propósito específico, compreender as questões econômicas, legais e sociais que envolvem o uso da informação, e acessar e utilizar as informações eticamente e legalmente (ELMBORG, 2012, p. 87, tradução nossa).

Ao desenvolver tais características, não só as/os profissionais da informação e documentação, como também as mulheres, tornam-se aptas/os, orientadas/os e inclinadas/os a intervir como indivíduo crítico e consciente de sua capacidade de entender a importância e alcance da informação.

Com efeito, a complexa gama de processos individuais e coletivos, no trato humano e profissional da Competência em Informação, constrói um campo fértil que deve ser associado à ética. Nessa acepção, o conceito de Ética em Informação precisa ser conformado no campo da $\mathrm{Cl}$ perpassando pela $\mathrm{Al}$, da qual decorre a El.

Segundo Sánchez Vázquez, "a ética é a teoria ou ciência do comportamento moral dos homens em sociedade. Ou seja, é ciência de uma forma específica de comportamento humano" (VÁZQUEZ, 2014, p. 23).

Entende-se, então, que a ética estuda as atitudes do sujeito, explorando e analisando se os atos praticados são morais ou amorais ou, ainda, se estão dentro do que se pode conceituar como o exercício de preceitos éticos e não éticos.

Para tanto, Capurro (2010) aduz que os interesses da ética se cruzam com os das ciências e da sociologia. Contudo, diferencia-se deles por sua capacidade de abrir uma lacuna crítica no atual ambiente moral normativo, implícito ou explícito.

Logo, é notório que o indivíduo, profissional da informação e documentação ou não, seja em contexto universal, particular ou singular, tenha noção do que é certo ou errado, cabendo às atitudes morais ilustrarem suas percepções e ações.

Na acepção geral sobre ética, Marcondes faz saber que:

\footnotetext{
A problemática da ética, portanto, em um sentido amplo, diz respeito à determinação do que é certo ou errado, bom ou mau, permitido ou proibido, de acordo com um conjunto de normas ou valores adotados historicamente por uma sociedade. Esta definição é importante porque o ser humano deve agir de acordo com tais valores para que sua ação possa ser considerada ética. Desta forma se introduz uma das noções mais fundamentais da ética: a do dever (MARCONDES, 2015, p. 9).
}

Nessa circunstância, concebe-se que as condutas morais ratificadas por normas, valores e costumes determinam as práticas sociais que, perpetradas reiteradamente de forma generalizada e prolongada, resultam em certa convicção de obrigatoriedade. 
Por certo, as/os profissionais da informação e documentação não devem traçar preceitos éticos de análise dissociados das informações que permeiam as realidades jurídica, social, econômica e política concretas vivenciadas pelos indivíduos e amoldadas na Al.

Dessa forma González de Gómez explica que:

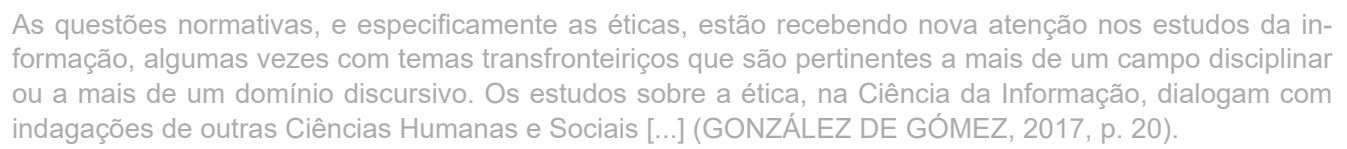

Assim, a ética em informação está permeando diversos campos, fazendo com que estudos recentes na $\mathrm{Cl}$ contemplem suas interfaces com a epistemologia, o direito e a política.

Nesse seguimento, Schneider; Brisola e Silva Jr. asseveram que "a ética em informação é então uma ética da política, que deve poder cercear o abuso de poder e orientar seu uso responsável, cidadão, no contexto das diversas práticas informacionais" (SCHNEIDER; BRISOLA; SILVA JR., 2017, p. 1).

Em referência a tais perspectivas, Schneider explica que a organização do conhecimento, pormenorizada pela $\mathrm{Cl}$,

\begin{abstract}
[...] revela seu caráter estratégico decisivo, tanto na cooperação quanto no conflito que perpassam o jogo político, dado o papel capital da informação nas disputas de poder, o que engloba conhecimentos adequados das forças em disputa (seus recursos, fraquezas, projetos), acesso menos ou mais privilegiado a dados econômicos, científicos ou militares, posse de documentos comprometedores do adversário [...] difusão ou silenciamento de mensagens, falsas ou verdadeiras, capazes de mobilizar (ou desmobilizar) amplos contingentes da população, ou mesmo poucos indivíduos situados em posições de força etc. (SCHNEIDER, 2013, p. 63)
\end{abstract}

Corroborando tal assertiva, aprecia-se a proposta de González de Gómez de reunir produtivamente ética, direito e política: "a ética, porque coloca a dignidade humana como crivo de valorização do valor; a política, porque constrói um 'nós' de compromissos abrangentes; o direito, porque dá uma forma positiva às proposições solidárias mas sem força de aplicação das normas éticas e morais" (GONZÁLEZ DE GÓMEZ, 2010, p. 160).

Enquanto muitos profissionais dedicam-se intensamente à implementação da Ética em Informação, outros grupos vêm buscando refutar a ideia de que toda informação tratada na rede precisa seguir os preceitos éticos.

\title{
3 Metodologia
}

A pesquisa é de caráter exploratório por buscar o desvelamento do trabalho desenvolvido por profissionais da informação e documentação quanto à El, na Al do portal da Câmara dos Deputados. Segundo Gil, a pesquisa exploratória visa

\footnotetext{
[...] proporcionar maior familiaridade com o problema com vistas a torná-lo explícito ou a construir hipóteses. Pode-se dizer que estas pesquisas têm como objetivo principal o aprimoramento de idéias ou a descoberta de intuiç̃oes. Seu planejamento é, portanto, bastante flexível, de modo que possibilite a consideração dos mais variados aspectos relativos ao fato estudado (GIL, 2008, p. 41).
}

O estudo possui delineamento bibliográfico para embasamentos teórico e documental sobre Encontrabilidade da Informação (findability) e Al, na perspectiva interdisciplinar da $\mathrm{Cl}$, considerando as teorias da Competência em Informação e da Ética em Informação. Segundo Gil, a pesquisa bibliográfica é "[...] desenvolvida com base em material já elaborado, constituído principalmente de livros e artigos científicos" (GIL, 2008, p. 44).

A diferença entre o corpus da pesquisa bibliográfica e documental está na natureza das fontes, pois, num primeiro momento, vale-se de materiais que passaram por avaliação e tratamento analítico; no segundo, lida-se com aqueles que ainda não receberam um tratamento analítico ou que, ainda, podem ser reelaborados de acordo com a problemática da pesquisa (GIL, 1999).

Utiliza-se o método indutivo com abordagem qualitativa para realizar a verificação de particularidades que envolvem a compreensão da informação digital, que podem se encontrar pervasivas ou não. A abordagem qualitativa, na interpretação de Minayo (2001), trabalha com o universo de significados, motivos, aspirações, crenças, valores e atitudes, o que corresponde a um espaço mais profundo das relações, dos processos e dos fenômenos que não podem ser reduzidos à operacionalização de variáveis. 
Para avaliar a qualidade da informação, realiza-se mapeamento das interfaces que disponibilizam informações legislativas, no portal da Câmara dos Deputados, sobre as proposições que tratam dos Direitos das Mulheres.

\section{Resultados}

Constata-se a existência de diferentes ambientes na Al do portal da Câmara dos Deputados, com possibilidades de Encontrabilidade de Informações semelhantes sobre os Direitos das Mulheres, que ora se completam, ora se apresentam conflituosas, exigindo que os dados legislativos disponibilizados sejam confirmados a partir da verificação de autoria das proposições, datas de propositura, tramitação e arquivamento ou conversão em lei.

AAl do portal possui 4 (quatro) categorias: "Institucional", "Deputados", "Atividades Legislativas" e "Comunicação". Possui ainda uma classificação por "Temas", possibilidade de "acessibilidade", de contato pelo "Fale Conosco" e ainda o "Acesso à Informação".

Os Direitos da Mulheres estão em debate na Câmara do Deputados por meio de proposições. As informações normativas referentes a tais proposições estão previstas no Regimento Interno da Câmara dos Deputados (RICD), dos artigos 100 a 107, combinados com as prescrições da Constituição Federal de 1988 (BRASIL, Congresso, Câmara dos Deputados, 2017; BRASIL, 1988).

Entende-se por proposição toda matéria sujeita à deliberação da Câmara dos Deputados. Consideram-se proposições: Proposta de Emenda à Constituição (PEC), Projeto de Lei Complementar (PLP), Projeto de Lei (PL), Projeto de Lei de Conversão (PLV), Projeto de Decreto Legislativo (PDC), Projeto de Resolução (PRC), Medida Provisória (MPV); Requerimento (REQ), Requerimento de Informação (RIC), Requerimento de Instituição de CPI (RCP), Indicação (INC), Recurso, Parecer e Proposta de Fiscalização e Controle (BRASIL, Congresso, Câmara dos Deputados, 2017).

As proposições deverão sempre ser redigidas com clareza, em termos explícitos e concisos, e apresentadas em três vias. As proposições podem ter origem em entes dos Poderes Executivo, Legislativo e Judiciários (BRASIL, Congresso, Câmara dos Deputados, 2017; BRASIL, 1988).

Terminando a legislatura, as proposições que em seu decurso tenham sido submetidas à deliberação da Câmara e ainda se encontrem em tramitação, bem como as que abram crédito suplementar, com pareceres ou sem eles, serão arquivadas. As exceções são as com pareceres favoráveis de todas as Comissões, as já aprovadas em turno único, em primeiro ou segundo turno, que tenham tramitado pelo Senado, ou dele originárias, de iniciativa popular, de iniciativa de outro Poder ou do Procurador-Geral da República. Contudo, a proposição poderá ser desarquivada mediante requerimento do autor, ou autores, dentro dos primeiros cento e oitenta dias da primeira sessão legislativa ordinária da legislatura subsequente, retomando a tramitação desde o estágio em que se encontrava (BRASIL, Congresso, Câmara dos Deputados, 2017).

Foram analisadas quatro interfaces/fontes de pesquisa encontradas no portal da Câmara dos Deputados, que disponibilizam as proposições em tramitação: "Fale Conosco", "Dados Abertos", "Pesquisas Simplificada e Avançada" e "Secretaria das Mulheres", a partir dos conceitos e atributos da El e Al em consonância com as concepções da Competência em Informação e da Ética em Informação sob a égide de que o governo brasileiro tem a intenção de atender os indicativos dos ODSs da Agenda 2030

\subsection{Fale Conosco}

No portal da Câmara dos Deputados, a possibilidade de contato pelo "Fale Conosco" está na página inicial. Esse canal de atendimento das demandas das/os cidadã/ãos é gerido pela Ouvidoria Parlamentar, que atende as prescrições do Regimento Interno da Câmara dos Deputados (RI) (Figura 1). 
Figura 1: Interface "Fale Conosco"
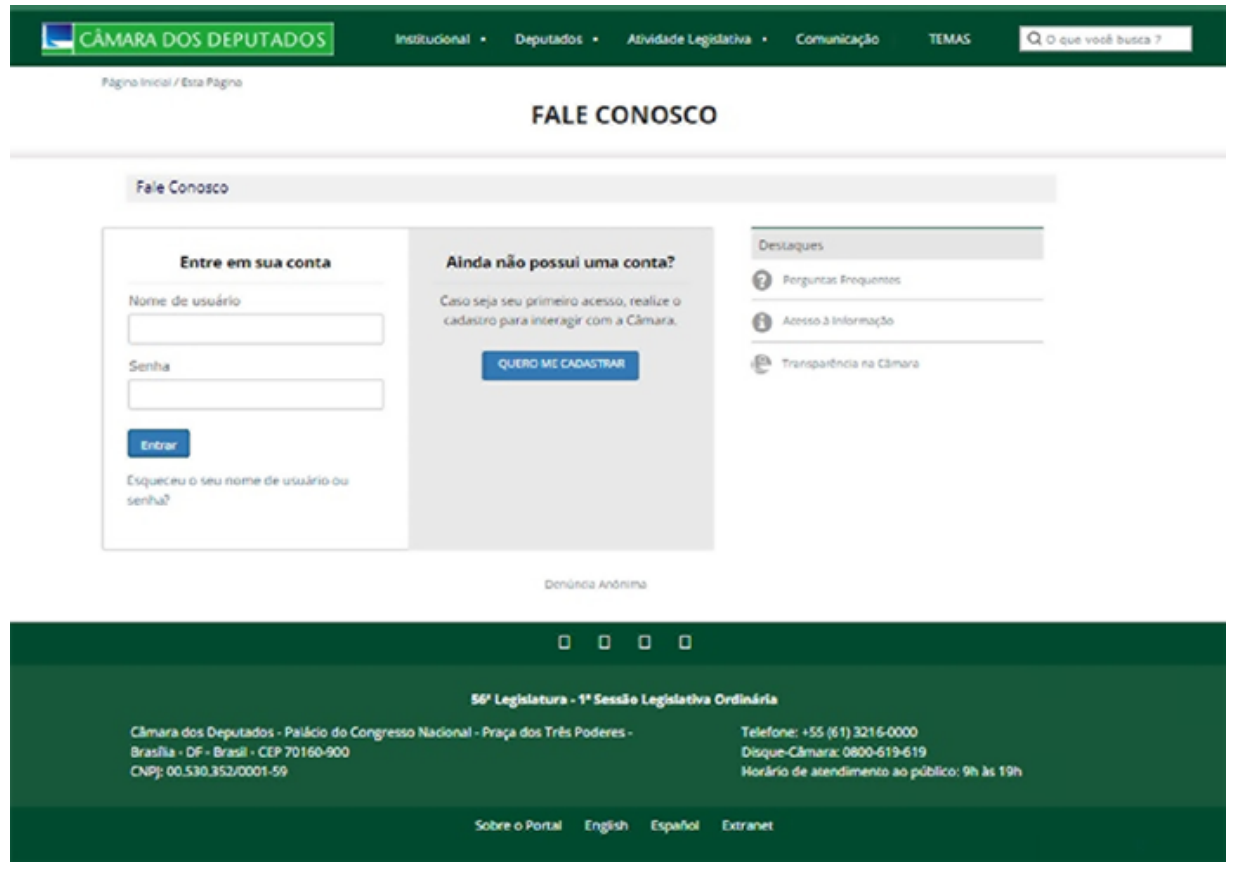

Fonte: BRASIL. Congresso Nacional. Câmara dos Deputados (2020).

De acordo com o Art. 21-A do RI, a Ouvidoria Parlamentar tem a competência de receber, examinar e encaminhar aos órgãos competentes as reclamações ou representações de pessoas físicas ou jurídicas sobre: violação ou qualquer forma de discriminação atentatória dos direitos e liberdades fundamentais; ilegalidades ou abuso de poder; mau funcionamento dos serviços legislativos e administrativos da Casa; assuntos recebidos pelo portal "Fale Conosco", pelos Correios (Praça dos Três Poderes - Anexo II - Ala C - Sala T-40 - 70.160-900/Brasília - DF) e pelo sistema Disque-Câmara 0800619619 de atendimento à população.

Pelo canal "Fale Conosco", disponibilizado pelo portal da Câmara dos Deputados, é possível fazer qualquer questionamento em atendimento à LAl e decreto regulamentador (Figura 1).

\subsection{Dados Abertos}

No portal da Câmara dos Deputados, a classificação dos "Dados Abertos" está na categoria "Institucional", na classe "Transparência" (Figura 2).

Figura 2: "Dados Abertos"

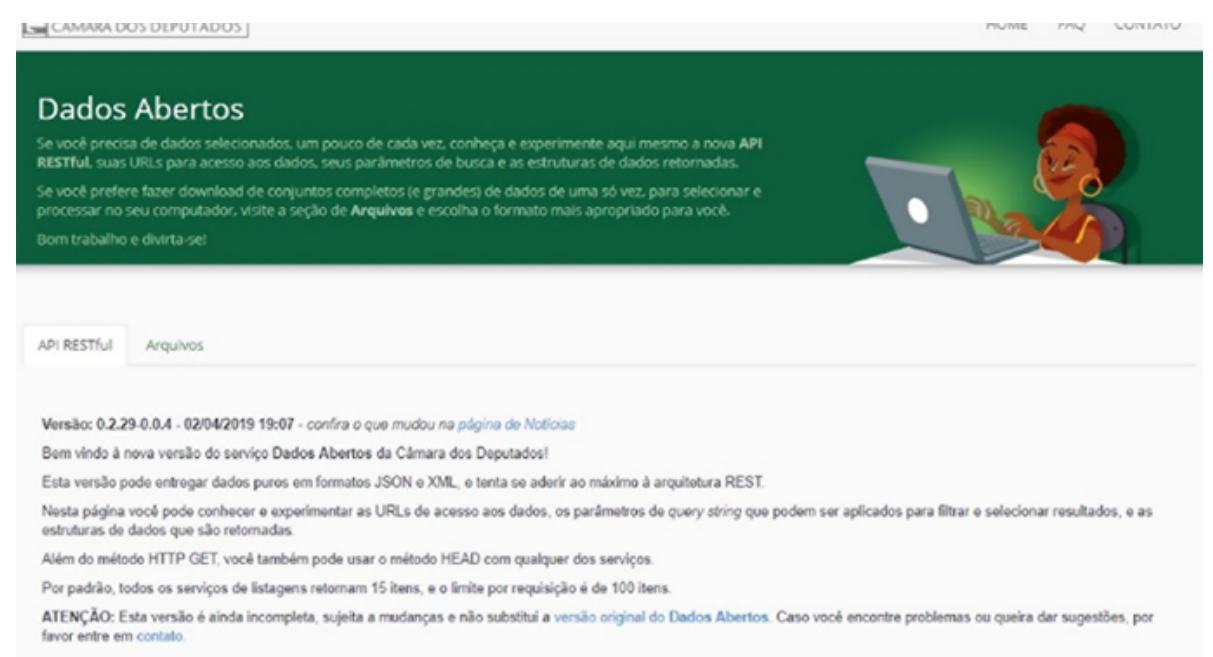

Fonte: BRASIL. Congresso Nacional. Câmara dos Deputados (2020). 
A nova versão do serviço "Dados Abertos", da Câmara dos Deputados, disponibiliza dados puros em formatos JSON e XML, e tenta se aderir ao máximo à arquitetura REST. É possível conhecer e experimentar as URLs de acesso aos dados, os parâmetros de query string que podem ser aplicados para filtrar e selecionar resultados, e as estruturas de dados que são retornadas. Além dos métodos HTTP GET e HEAD com qualquer dos serviços. Por padrão, todos os serviços de listagens retornam 15 itens, e o limite por requisição é de 100 itens (Figura 2).

\subsection{Pesquisas Simplificada e Avançada}

No portal da Câmara dos Deputados, a classificação "Pesquisa Simplificada e Avançada" está na categoria "Atividade Legislativa".

\subsubsection{Pesquisa Simplificada}

A "Pesquisa Simplificada", como já indicada na terminologia, apresenta um procedimento de pesquisa mais compreensível e fácil de ser executado.

Com a intenção de agilizar a busca, a "Pesquisa Simplificada" permite pesquisar pelo seguinte filtro "Palavra ou expressão de busca" o argumento textual a ser buscado.

Exemplo: LDB ou Lei de diretrizes e bases da educação.

A pesquisa textual abrange os seguintes campos: "Assunto", "Tipo de Proposição", "Número", "Ano", "Autor" e "Em tramitação - Todas - Sim - Não" (Figura 3).

Figura 3: "Pesquisa Simplificada"

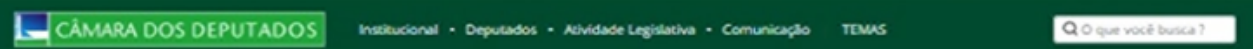

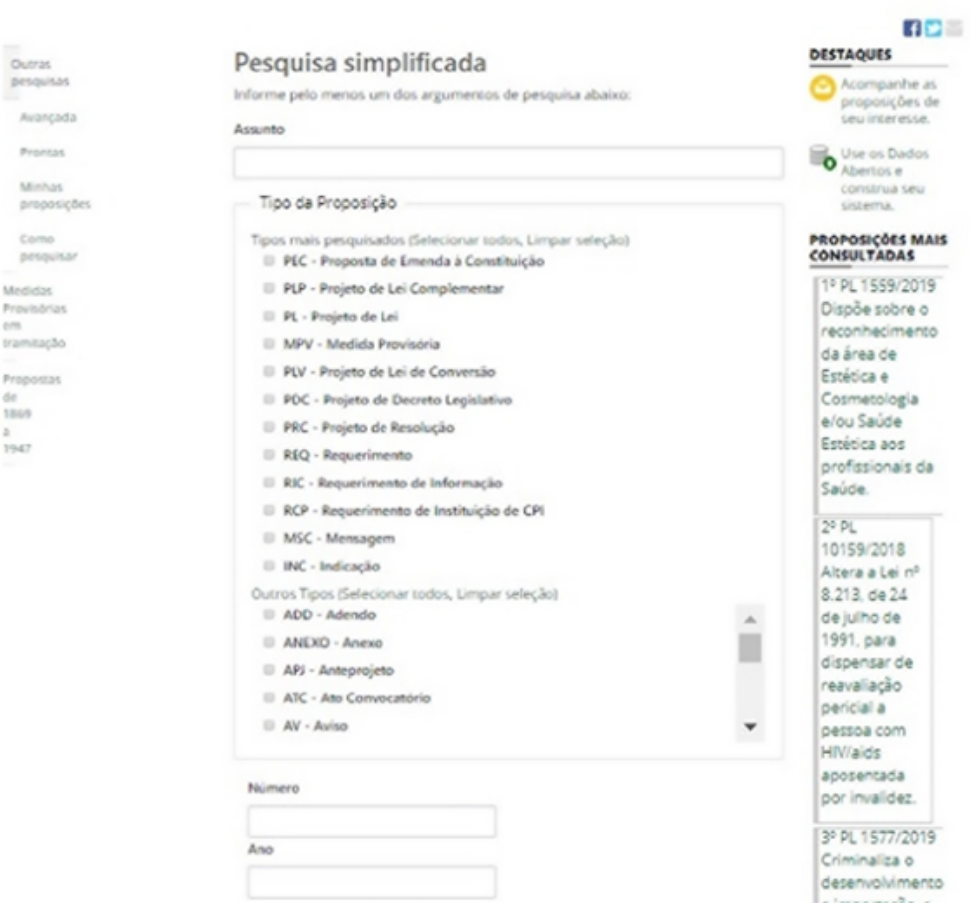

Fonte: BRASIL. Congresso Nacional. Câmara dos Deputados (2020).

No caso de pesquisa de expressões no campo de Assunto, o resultado seguirá o seguinte padrão:

Fundo de garantia - retorna os registros que contenham as palavras "Fundo", "de" e "garantia", independentemente da posição que apareçam no texto pesquisado; "Fundo de garantia" (com aspas duplas) - retorna os registros 
que contenham as palavras "Fundo", "de" e "garantia" juntas; Requer* - retorna os registros que iniciem com a palavra "Requer", tais como - Requerimento, Requerido, Requeridas etc.; "quer - retorna os registros que terminem com a palavra "quer", tais como Requer, Qualquer, Quaisquer etc.; "Tipo de norma": tipo de norma (lei ordinária, decreto, medida provisória etc.) (Figura 3).

\subsubsection{Pesquisa Avançada}

A "Pesquisa Avançada" permite usar um ou vários tipos de filtro para encontrar informações específicas. Possibilita uma investigação mais pormenorizada e de maneira aprimorada para conformação das necessidades mais acuradas das/os usuárias/os (Figura 4).

Figura 3: "Pesquisa Simplificada"

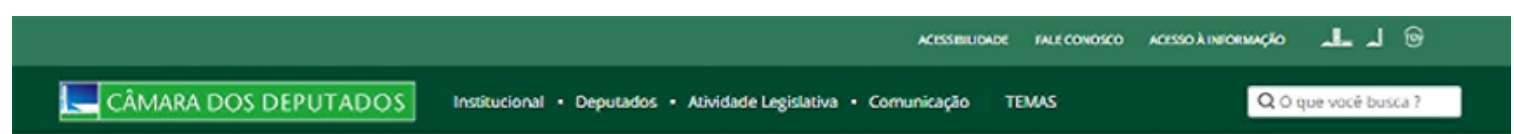

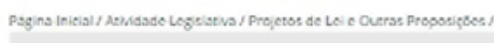

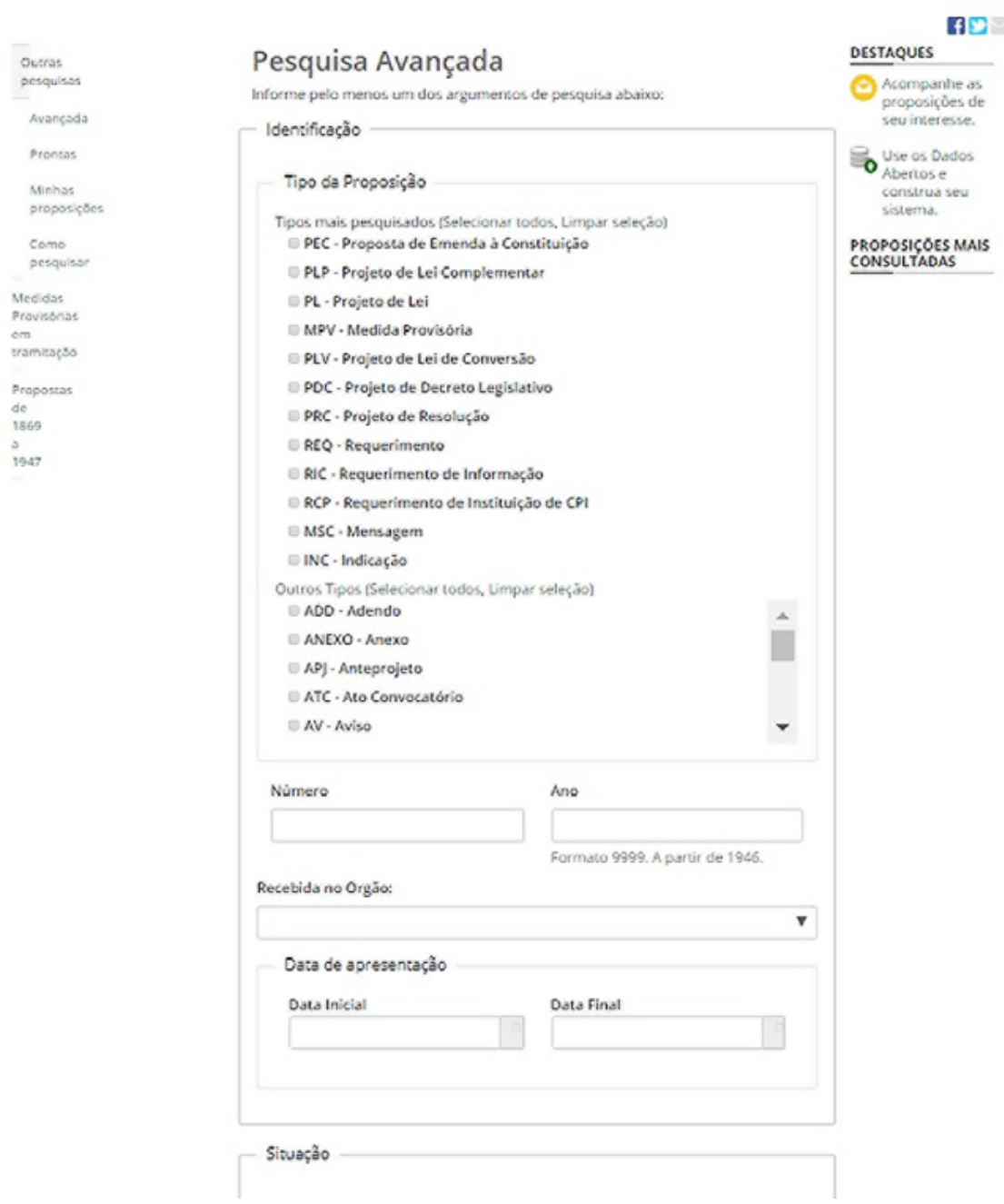

Fonte: BRASIL. Congresso Nacional. Câmara dos Deputados (2020).

Inicialmente, escolhe-se o "Tipo de Proposição", depois as opções "Número", "Ano", "Recebida no Órgão", "Data de Apresentação - Inicial - Final", Situação: "Em tramitação - Todas - Sim - Não", "Situação atual" "No órgão", "Assunto": "Todas estas palavras" - "Exatamente esta palavra ou expressão" - "Qualquer uma destas palavras" - "Nenhuma destas palavras", "Onde procurar": "Ementa" - "Indexação" - "Inteiro teor", "Autor": "Tipo" - "Autor" - "Partido do Autor" - "UF do Autor", "Relator": "Nome do Relator" - "Partido do Relator" - "UF do Relator" - No Órgão: "Período" - "Data Inicial” - "Data Final”, "Tramitação": "Expressão textual” - "No órgão" - "Período" - "Data Inicial" - "Data Final" (Figura 4). 


\subsection{Proposições sobre a mulher na Secretaria da Mulher}

A Secretaria da Mulher integra a estrutura organizacional da Câmara dos Deputados. Sua criação ocorreu em julho de 2013 e reuniu a Procuradoria da Mulher, criada em 2009, e a Coordenadoria dos Direitos da Mulher, que representava a Bancada Feminina.

No portal da Câmara dos Deputados, a classificação das "Proposições sobre a mulher na Secretaria da Mulher" está na categoria "Institucional", na classe "Papel e estrutura", na subclasse "Secretarias" (Figura 5).

Figura 3: "Pesquisa Simplificada"

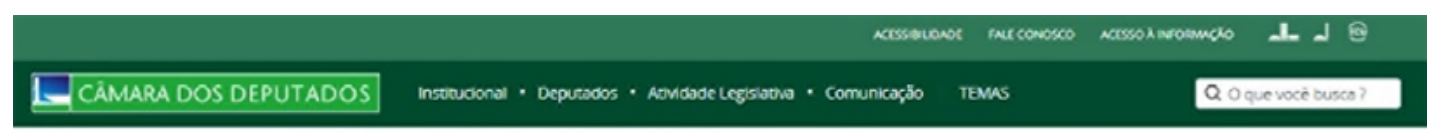

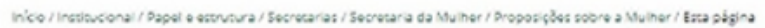

SECRETARIA DA MULHER

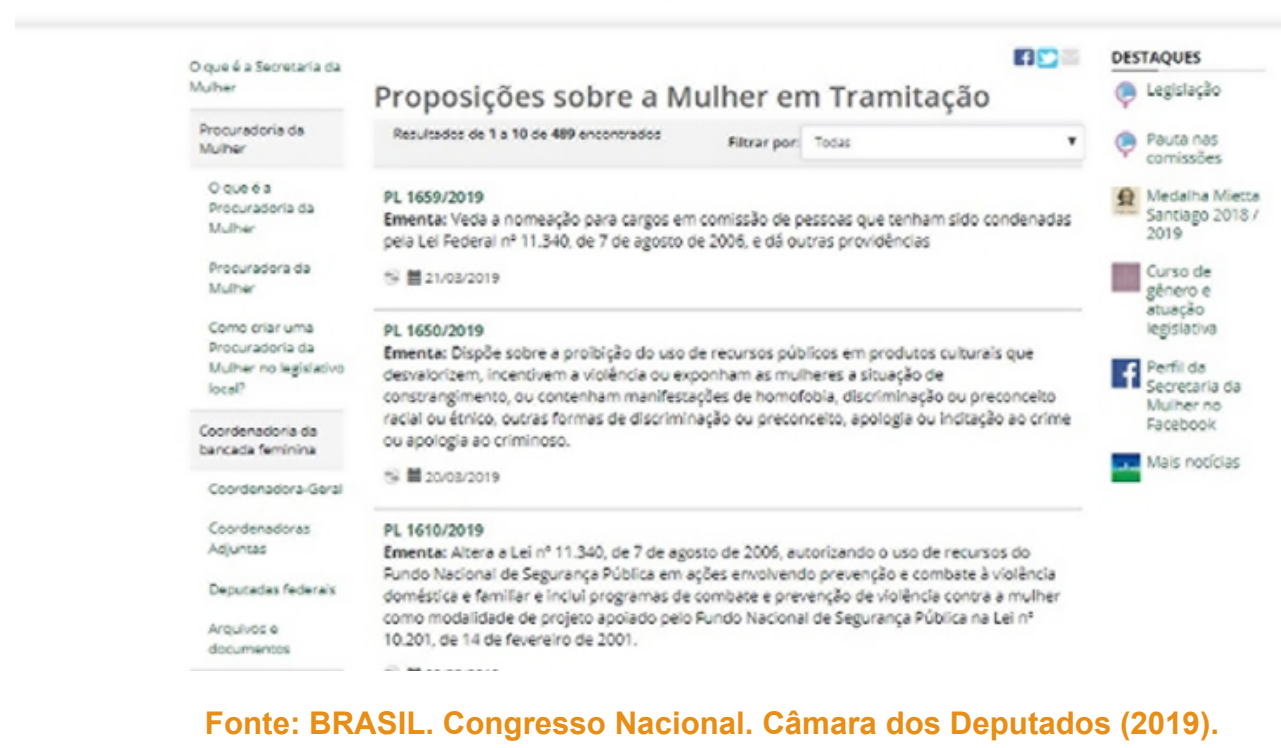

A pesquisa permite os seguintes filtros: "Todas", "Projeto de Lei (PL)", "Projeto de Lei Complementar (PLP)", "Medida Provisória (MPV)", "Proposta de Emenda à Constituição (PEC)", "Projeto de Decreto Legislativo (PDC)" e "Projeto de Resolução (PRC)" (Figura 5).

\section{Conclusões}

Foram identificadas inconsistências na indexação das proposições e divergências nas informações disponibilizadas, dificultando o exercício das transparências ativa e passiva apregoadas pela LAI.

Os menus das páginas internas, com taxonomias diferenciadas representando o mesmo conteúdo, prejudica a qualidade da Al e impossibilita a adequada $\mathrm{EI}$, dificultando o alcance dos objetivos evidenciados nessa pesquisa e que são preceituados na Agenda 2030.

Uma questão de maior relevância foi identificada na busca realizada na "Secretaria da Mulher" que diz disponibilizar todas as proposições, ditas em tramitação sobre a mulher. São apresentadas iniciativas arquivadas e que já foram convertidas em Lei, consequentemente induzindo a erro e disseminando informação equivocada quanto ao quantitativo apresentado.

Outra conclusão evidenciada, nesse mesmo canal "Secretaria da Mulher", é que, se a proposição em tramitação não traz o termo "mulher" no conteúdo de sua ementa, ou em seus termos indexadores, essa não é contemplada na gestão da informação da Secretaria, representando ausência de transparência efetiva e ética em informação questionável. 
Como exemplos, são citados a PEC n 164/12 e os PLs n 5069/13, n 1545/11 e n 7443/06 iniciados pelo ex-deputado federal Eduardo Cunha, que não fazem parte do compêndio das proposições relacionadas pela secretaria por não apresentarem nos parâmetros de busca (ementa e termos-chave) a palavra "mulher".

Tais fatos dificultam, e muito, a El sobre todos os direitos das mulheres em debate na Câmara dos Deputados, destacando, inclusive, ser a "Secretaria da Mulher" o principal órgão da Câmara do Deputados que defende as "principais bandeiras" das mulheres.

Alcançar a igualdade de gênero não é apenas um direito humano fundamental, mas a base necessária para a construção de um mundo pacífico, próspero e sustentável. O esforço de alcance do ODS 5 é transversal a toda a Agenda 2030 e reflete a crescente evidência de que a igualdade de gênero tem efeitos multiplicadores no desenvolvimento sustentável.

Assegurar o acesso público à informação e proteger as liberdades fundamentais, em conformidade com a legislação nacional e os acordos internacionais, é uma das metas do ODS 16, que pretende promover instituições fortes, inclusivas e transparentes, a manutenção da paz e o respeito aos direitos humanos baseados no Estado de direito para o desenvolvimento humano sustentável.

Por isso, dependendo da escolha entre as quatro interfaces apresentadas, os dados recuperados com os mesmos parâmetros de busca resultam em informações diferentes, prejudicando a El sobre os Direitos das Mulheres debatidos na Câmara dos Deputados.

As/os profissionais da informação e documentação do portal aplicam uma taxonomia conflituosa enquanto estrutura classificatória, para a organização do conhecimento no que tange aos interesses e direitos das mulheres , que não atende aos ODSs e termina por negligenciar os atributos da Competência em Informação e da Ética em Informação abordados pela Ciência da Informação.

Este artigo, de forma alguma, pretende esgotar as ilações decorrentes das questões abordadas, mas, sim, apresentar uma contribuição para se pensar a encontrabilidade das informações sobre os Direitos das Mulheres debatidos na Câmara dos Deputados, a Al do portal e os conceitos de Competência em Informação e Ética em Informação, agregando questões sociais e jurídicas relacionadas à informação como instrumentos-chave para a mulher superar os obstáculos que a persegue desde a antiguidade.

\section{Referências}

ASSOCIATION OF COLLEGE AND RESEARCH LIBRARIES (CC BY-NC-SA 4.0). Framework for Information Literacy for Higher Education. ACRL Board, 11 jan. 2016. Disponível em: <http://www.ala.org/acrl/sites/ala.org.acrl/ files/content/issues/infolit/Framework_ILHE.pdf>. Acesso em: 29 jan. 2020.

BOTELHO-FRANCISCO, Rodrigo Eduardo. Literacias emergentes em contextos digitais. Revista Brasileira de Biblioteconomia e Documentação, São Paulo, v. 13, p. 4-26, jan. 2017. ISSN 1980-6949. Disponível em: <https:// rbbd.febab.org.br/rbbd/article/view/653/568>. Acesso em: 29 jan. 2020.

BRASIL. Portal da Câmara dos Deputados. Disponível em: <http://www.camara.leg.br/>. Acesso em: 10 jan. 2019.

BRASIL. Congresso. Câmara dos Deputados. Fale Conosco. Disponível em: <https://camara.custhelp.com/app/ utils/login form/redirect/home>. Acesso em: 29 jan. 2020.

BRASIL. Congresso. Câmara dos Deputados. Dados Abertos. Disponível em: < $\underline{\text { https://dadosabertos.camara.leg. }}$ br/swagger/api.html>. Acesso em: 29 jan. 2020.

BRASIL. Congresso. Câmara dos Deputados. Pesquisa Simplificada. Disponível em: < https://www.camara.leg.br/ buscaProposicoesWeb/pesquisaSimplificada>. Acesso em: 29 jan. 2020.

BRASIL. Congresso. Câmara dos Deputados. Pesquisa Avançada. Disponível em: <https://www.camara.leg.br/ buscaProposicoesWeb/pesquisaAvancada>. Acesso em: 29 jan. 2020. 
BRASIL. Congresso. Câmara dos Deputados. Regimento Interno da Câmara dos Deputados: aprovado pela Resolução $n^{\circ}$ 17, de 1989, e alterado até a Resolução n 20, de 2016. 18 ed. Edições Câmara: Brasília, 2017. Disponível em: <http://bd.camara.gov.br/bd/handle/bdcamara/18847>. Acesso em: 29 jan. 2020.

BRASIL. Congresso. Câmara dos Deputados. Secretaria das Mulheres. Disponível em: <http://www2.camara.leg. br/a-camara/estruturaadm/secretarias/secretaria-da-mulher/proposicoes-sobre-a-mulher/todas>. Acesso em: 29 jan. 2020.

BRASIL. Constituição da República Federativa do Brasil: texto constitucional promulgado em 5 de outubro de 1988, com as alterações pelas emendas constitucionais nos 1/92 a 53/2006 e pelas emendas constitucionais de revisão nos 1 a 6/94. Diário Oficial da União, Brasília, DF, 5 out. 1988.

BRISOLA, Anna Cristina; SCHNEIDER, Marco André Feldman; SILVA JÚNIOR, Jobson Francisco da. Competência crítica em informação, ética intercultural da informação e cidadania global na era digital: fundamentos e complementaridades. In: ENCONTRO NACIONAL EM PESQUISA EM CIÊNCIA DA INFORMAÇÃO, 18, 2017, Marília. Anais [...]. Marília: UNESP, 2017. Disponível em: <http://enancib.marilia.unesp.br/index.php/xviiienancib/ ENANCIB/paper/view/417>. Acesso em: 29 jan. 2020.

CAPURRO, Rafael. On the Genealogy of Information. In: KORNWACHS, K.; JACOBY, K. (Eds.). Information: new questions to a multidisciplinary concept. Berlin, Germany: Akademie Verlag, 1996. Disponível em: < $\underline{\text { http://www. }}$ capurro.de/cottinf.htm>. Acesso em: 1 maio. 2017.

CAPURRO, Rafael. Desafíos teóricos y prácticos de la ética intercultural de la información. In: SIMPÓSIO BRASILEIRO DE ÉTICA DA INFORMAÇÃO, 2010, João Pessoa. Anais... João Pessoa: PPGCI/UFPB, 2010. Disponível em: <http://www.capurro.de/paraiba.html>. Acesso em: 29 jan. 2020.

ELMBORG, James. Critical information literacy: definitions and challenges. Chicago: Association of College \& Research Libraries, 2012.

GIL, Antônio Carlos. Como elaborar projetos de pesquisa. 4 ed. São Paulo: Atlas, 2008.

GIL, Antônio Carlos. Métodos e técnicas de pesquisa social. 5 ed. São Paulo: Atlas, 1999.

GONZÁLEZ DE GÓMEZ, Maria Nélida. Perspectivas em ética da informação: acerca das premissas, das questões normativas e dos contextos da reflexão. In. FREIRE, Gustavo Henrique de Araújo (Org.) Ética da Informação, Conceitos, Abordagens, Aplicações. João Pessoa: Ideia, p. 147-163, 2010.

GONZÁLEZ DE GÓMEZ, Maria Nélida. Reflexões sobre ética da informação: panorama contemporâneo. GONZÁLEZ DE GÓMEZ, Maria Nélida; CIANCONI, Regina de Barros (Orgs.). Ética da informação: perspectivas e desafios. Rio de Janeiro: Editora Garamond: Niterói: PPGCI/UFF, 2017. Cap. 1, p. 19-44.

GUIMARÃES, J. A. C. A dimensão teórica do tratamento temático da informação. Revista Ibero-americana de Ciência da Informação (RICI), v.1, n.1, p. 77-99, jan./jun. 2008.

INFORMATION ARCHITECTURE INSTITUTE. What is Information Architecture? 2020. Disponível em: <https:// www.iainstitute.org/what-is-ia>. Acesso em: 29 jan. 2020.

MARCONDES, Danilo. Textos básicos de ética: de Platão a Foucault, Rio de Janeiro: Zahar, 2007.

MINAYO, Maria Cecília de Souza (Org.). Pesquisa social: teoria, método e criatividade. Petrópolis: Vozes, 2001.

MORVILLE, Peter. Ambient findability. Sebastopol O'eally, 2005.

ORGANIZAÇÃO DAS NAÇÕES UNIDAS BRASIL. Transformando o nosso mundo: a agenda para o desenvolvimento sustentável de 2030, out. 2015. Disponível em: <https://nacoesunidas.org/pos2015/agenda2030/>. Acesso em: 23 jan. 2019. 
ROSENFELD, Louis; MORVILLE, Peter. Information architecture for the world wide web. 3. Cambridge: O'Reilly, 2006.

SANCHEZ VÁZQUEZ, A. Ética. Rio de Janeiro: Editora Civilização Brasileira, 2014.

SARACEVIC, Tefko. Ciência da informação: origem, evolução e relações. Perspectivas em Ciência da Informação, Belo Horizonte, v. 1, n. 1, p. 41-62, jan./jun. 1996.

SCHNEIDER, Marco André Feldman. A dialética do gosto: informação, música e política. Rio de Janeiro: Faperj/ Circuito, 2015.

SCHNEIDER, Marco André Feldman. Ethics and epistemology: warning against the "axiological neutrality" on contemporary communication research. Matrizes, v. 7, p. 221-234, $2013 a$.

SCHNEIDER, Marco André Feldman. Ética, política e epistemologia: interfaces da informação. In: ALBAGLI, Sarita (Org.). Fronteiras da Ciência da Informação. Brasília: Ibict, p. 57-77, 2013 b.

VECHIATO, Fernando Luiz. Encontrabilidade da informação: contributo para uma conceituação no campo da Ciência da Informação. 2013. 206 f. Tese (Doutorado em Ciência da Informação) - Faculdade de Filosofia e Ciências, Universidade Estadual Paulista, Marília, 2013.

VECHIATO, Fernando Luiz; VIDOTTI, Silvana Aparecida Borsetti Gregorio. Encontrabilidade da Informação: atributos e recomendações para ambientes informacionais digitais. Informação \& Tecnologia, v. 1, n. 2, p. 42-58, 2014a. Disponível em: <http://hdl.handle.net/11449/114982>. Acesso em: 29 jan. 2020.

VECHIATO, Fernando Luiz; VIDOTTI, Silvana Aparecida Borsetti Gregorio. Encontrabilidade da informação. São Paulo: Cultura Acadêmica, 2014b. (Coleção PROPG Digital UNESP). Disponível em: < http://hdl.handle. net/11449/126218>. Acesso em: 29 jan. 2020.

VIOLA, Carla Maria Martellote. Transparência da Informação e Ética da Comunicação: um estudo político-social sobre o portal da Câmara dos Deputados. In: ENCONTRO NACIONAL DA ULEPICC-BRASIL, 6., 2016, Brasília. Anais [...]. Brasília: UnB, 2016. p. 36-50. Disponível em: < https://ulepiccbrasiliadotcom.files.wordpress. com/2017/04/ulepicc2016 anaisgt6.pdf>. Acesso em: 29 jan. 2020.

VITORINO, Elizete Vieira; PIANTOLA, Daniela. Dimensões da Competência Informacional. Ciência da Informação, [S.I.], v. 40, n. 1, mar. 2012. ISSN 1518-8353. Disponível em: <http://revista.ibict.br/ciinf/article/view/1328>. Acesso em: 29 jan. 2020. 


\section{Dados dos autores}

Carla Maria Martellote Viola

Bolsista de Produtividade CNPq. Cientista do Nosso Estado Faperj. Pesquisador titular do Instituto Brasileiro de Informação em Ciência e Tecnologia (lbict). Professor associado do departamento de Comunicação Social da Universidade Federal Fluminense (UFF-Niterói-RJ). Professor do quadro permanente do Programa de Pós-Graduação em Ciência da Informação - PPGCI-Ibict/ECO-UFRJ e do Programa de Pós-Graduação Mídia e Cotidiano - PPGMC-UFF. Doutor em Ciências da Comunicação pela Universidade de São Paulo (ECA-USP-2008). Mestre em Comunicação e Cultura pela Universidade Federal do Rio de Janeiro (ECO-UFRJ-2003). Bacharel em Comunicação Social, com habilitação em Produção Editorial (ECO-UFRJ-1999). Possui estágio pós-doutoral em Estudos Culturais, pelo Programa Avançado de Cultura Contemporânea (PACC) da Universidade Federal do Rio de Janeiro (UFRJ-2012), onde atua como pesquisador convidado, supervisionando estágios pós-doutorais. Autor do livro "A Dialética do Gosto: informação, música e política ", publicado em 2015 pela Editora Circuito, com bolsa de auxílio a publicação, da Faperj. Publicou também um livro de poesia e dezenas de artigos científicos, em capítulos de livros, anais de congressos e periódicos científicos, nacionais e internacionais. Vencedor dos concursos de ensaio Pensar a Contracoriente (Cuba-2003) e Mário Pedrosa, sobre arte e cultura contemporâneas (Brasil-2010). Professor universitário desde 2003. Interesses atuais de pesquisa: ética, política, epistemologia, competência crítica em informação e literacia midiática. Líder do grupo de pesquisa Perspectivas Filosóficas em Informação (Perfil-i). Representante da América Latina e Caribe no Conselho Consultivo do International Center for Information Ethics (ICIE). Pesquisador da Rede Mussi (Rede Franco-Brasileira de Pesquisadores em Mediações e Usos Sociais de Saberes e Informação). Membro dos grupos de pesquisa Estudos críticos em informação e organização social (Escritos) e Centro de Pesquisas e Produção em Comunicação e Emergência (Emerge) e do Laboratório em Rede de Humanidades Digitais (Larhud). No biênio 2017-2018, foi Diretor Científico da União Latina de Economia Política da Informação, Comunicação e Cultura, capítulo Brasil, e Coordenador do PPGCl-Ibict/ECO-UFRJ. Músico e escritor.

viola.carla@gmail.com

\section{Marco André Feldman Schneider}

Bolsista de Produtividade CNPq. Cientista do Nosso Estado Faperj. Pesquisador titular do Instituto Brasileiro de Informação em Ciência e Tecnologia (lbict). Professor associado do departamento de Comunicação Social da Universidade Federal Fluminense (UFF-Niterói-RJ). Professor do quadro permanente do Programa de Pós-Graduação em Ciência da Informação - PPGCl-Ibict/ECO-UFRJ e do Programa de Pós-Graduação Mídia e Cotidiano - PPGMC-UFF. Doutor em Ciências da Comunicação pela Universidade de São Paulo (ECA-USP-2008). Mestre em Comunicação e Cultura pela Universidade Federal do Rio de Janeiro (ECO-UFRJ-2003). Bacharel em Comunicação Social, com habilitação em Produção Editorial (ECO-UFRJ-1999). Possui estágio pós-doutoral em Estudos Culturais, pelo Programa Avançado de Cultura Contemporânea (PACC) da Universidade Federal do Rio de Janeiro (UFRJ-2012), onde atua como pesquisador convidado, supervisionando estágios pós-doutorais. Autor do livro "A Dialética do Gosto: informação, música e política ", publicado em 2015 pela Editora Circuito, com bolsa de auxílio a publicação, da Faperj. Publicou também um livro de poesia e dezenas de artigos científicos, em capítulos de livros, anais de congressos e periódicos científicos, nacionais e internacionais. Vencedor dos concursos de ensaio Pensar a Contracoriente (Cuba-2003) e Mário Pedrosa, sobre arte e cultura contemporâneas (Brasil-2010). Professor universitário desde 2003. Interesses atuais de pesquisa: ética, política, epistemologia, competência crítica em informação e literacia midiática. Líder do grupo de pesquisa Perspectivas Filosóficas em Informação (Perfil-i). Representante da América Latina e Caribe no Conselho Consultivo do International Center for Information Ethics (ICIE). Pesquisador da Rede Mussi (Rede Franco-Brasileira de Pesquisadores em Mediações e Usos Sociais de Saberes e Informação). Membro dos grupos de pesquisa Estudos críticos em informação e organização social (Escritos) e Centro de Pesquisas e Produção em Comunicação e Emergência (Emerge) e do Laboratório em Rede de Humanidades Digitais (Larhud). No biênio 2017-2018, foi Diretor Científico da União Latina de Economia Política da Informação, Comunicação e Cultura, capítulo Brasil, e Coordenador do PPGCl-Ibict/ECO-UFRJ. Músico e escritor.

marcoschneider@ibict.br

Received: $2020-02-20$

Accepted: $2020-11-29$

\section{(c) $)$ EY}

This work is licensed under a Creative Commons Attribution 4.0 United States License.

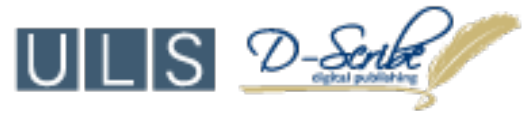

This journal is published by the University Library System of the University of Pittsburgh as part of its D-Scribe Digital Publishing Program and is cosponsored by the University of Pittsburgh Press 